\title{
Placental pathology and hypospadias
}

\author{
Yan Chen ${ }^{1,2}$, Luming Sun ${ }^{3}$, Hongquan Geng ${ }^{4}$, Xiaoping Lei' and Jun Zhang ${ }^{1,5}$
}

BACKGROUND: Studies have shown that hypospadias is associated with placenta-mediated pregnancy complication (PMPC). The role of placental lesions is still unclear. We aimed to examine the association between hyposadias and placental pathology, and the effect of PMPC.

METHODS: Using data from the US Collaborative Perinatal Project in 1959-1966, we identified 15,780 male subjects (167 hypospadias) for analysis. Detailed placental examinations were conducted following a standard protocol. Subjects were divided into two groups according to whether they had PMPC, including small-for-gestational-age, pre-eclampsia/eclampsia or placental abruption. Logistic regression models were used to explore the association.

RESULTS: The prevalence of hypospadias was two times higher in subjects with PMPC than those without. Compared to pregnancies with PMPC but no hypospadias, those with both PMPC and hypospadias had significant higher prevalence of placental lesions, such as low placental weight, vascular lesions, villous lesions, and membranous insertion of cord (adjusted odds ratio (OR) ranging from 2.6 to 5.2) after adjusting for potential confounders. In subjects without PMPC, no significant difference of placental pathology was found between those with or without hypospadias.

CONCLUSION: About one third of hypospadias cases were complicated with PMPC and had a higher risk of placental lesions, suggesting heterogeneity of hypospadias etiology and mechanisms.

$\mathbf{H}$ ypospadias is a common congenital malformation of male genitalia when the urethral opening is located on the coronary sulcus, ventral penile shaft or, in some cases, the scrotum or perineum, rather than at the tip of the penis (1). The prevalence is estimated at approximately 3-8 per 1,000 births (1-4). In a normal male fetus, genetic programming contributes to androgenic stimulation that induces posterior fusion of the genital folds and genital tubercle develops into a phallic structure (5). The embryological basis of hypospadias is the failure of midline fusion of the urethral fold.

Epidemiologic studies showed that the etiology of hypospadias is multifactorial. Aside from genetic, endocrine factors, environmental disruptors, hypospadias is found to be more common in adverse complications, such as pre-eclampsia/ eclampsia, small-for-gestational-age (SGA), placental abruption, multiple pregnancy, and preterm birth $(2,6-8)$. Most of these conditions were associated with placental insufficiency, presenting in a blood flow disorder marked by a reduction in the maternal/fetal exchange (7,9-11). The first three conditions were defined as placenta-mediated pregnancy complication (PMPC) (9,10). These conditions have similar pathophysiologic mechanisms attributable to diseased placental vessels, abnormal placental shapes, inadequate uteroplacental circulation, or abnormal placental development (10). As a result, the placental pathology may play an important role in the etiology of hypospadias. However, few studies further investigated the association between hypospadias and placental pathology because pathologic examinations were not available in most studies. To our knowledge, two case-control studies with small sample size were carried out exclusively in subjects with poor intrauterine growth and unable to draw reliable conclusions on the relationship due to insufficient statistical power $(9,12)$.

The current study used data from the Collaborative Perinatal Project (CPP) to explore if and to what extent hypospadias may have placental etiology. The CPP remains one of the most comprehensive sources of detailed placental pathology with the largest placental database in the world.

\section{METHODS \\ Population}

The CPP was a prospective cohort study that recruited pregnant women from 1959 to 1966 at 12 university-based academic centers across the United States. A detailed description of the study has been provided elsewhere (13). Women were enrolled at their first prenatal visit, at a mean gestation of $21.3 \pm 8.4 \mathrm{wk}$. In-depth demographic, socioeconomic, and behavioral information was collected by in-person interview at entry. Obstetrical factors were determined by the medical staff taking care of the women, and in the summary of the pregnancy. All ascertainments were reviewed and confirmed based on prespecified criteria by a senior study obstetrician at each site. Following delivery, placental gross morphology was examined and samples were collected for histological examination. Gross and microscopic examinations were conducted by trained pathologists according to a standard protocol. Children were systematically assessed for birth defects and other outcomes at birth and several interviews during the first $7 \mathrm{y}$. Seventy-five percent of children had complete follow-up (13). Hypospadias was diagnosed within the first 


\section{Articles Chen etal.}

$7 \mathrm{y}$ of life and the medical records were abstracted from the three diagnostic summaries: neonatal period, first year of life and $1 \mathrm{y}$ to $7 \mathrm{y}$ of age in CPP. The degree of hypospadias was, however, not recorded in the medical records. The CPP has one of the most comprehensive sources of detailed placental pathology and is still the largest placental database with a systematic follow-up of the children.

Of the 57,638 singleton pregnancies recruited in CPP, 27,407 boys were identified (Figure 1). Boys with an uncertain diagnosis of hypospadias or placental pathology unavailable were excluded. Subjects with an implausible combination of birth weight-for-gestational-age were excluded due to likely errors in gestational age; so were those with missing values on birth weight or gestational age (14). Patients with other major anomalies (including congenital heart diseases, alimentary tract malformations, central nervous system malformations, congenital eye conditions, etc.) or congenital syndromes, were also excluded. The final study population consisted of 167 hypospadias cases and 15,613 controls (Figure 1). The anonymized and de-identified study data files are publicly available through the US National Archives. A local ethical review (Ethics Committee of Xinhua Hospital Affiliated to Shanghai Jiaotong University School of Medicine) was not required for using such data in our hospital.

\section{Placental Sample Collection}

Placental pathologic assessments in the CPP were performed by a team of specially trained pathologists according to a standardized protocol, written by Dr. Naeye (15). Pathologists first conducted a gross examination of freshly delivered placentas. Then a full-thickness placental sample was taken from a representative block of the central portion, $3-4 \mathrm{~cm}$ from the cord insertion. One umbilical cord sample, one membrane roll sample, and samples from significant gross abnormalities were also taken for microscopic examination. Pathologists conducting the placental examinations were blinded to the clinical course for $98 \%$ of gross and $97 \%$ of microscopic examinations. We created dichotomous variables for placental pathological lesions defined by the presence of one or more of 8 pathology measures on gross and microscopic examinations according to the literatures (16-18). These measures included low placental weight, vascular lesions, villous changes, maternal floor infarcts, type of cord insertion to placenta, inflammatory cell infiltration, hemorrhage of the maternal surface, and calcification throughout the cut surface. Low placental weight was defined as less than the 10th percentile for CPP placentas delivered at each gestational age. Placenta-to-birth weight ratio was calculated as the ratio of placental weight to birth weight multiplied by $100 \%$. High placenta-to-birth weight ratio was defined as placenta-to-birth weight ratio greater than the 90th percentile of CPP placentas at a given gestational week. Detailed definitions of other placental pathological lesions were listed in Table $\mathbf{1 .}$

\section{Covariates and Outcomes}

Maternal characteristics that could affect placental pathology and hypospadias were considered as potential confounders in this study, including race (White, African-American, and other), maternal age at delivery, marital status at pregnancy, maternal education levels $(\leq 9 \mathrm{y}$, 10-12 y, >12 y), number of previous deliveries, socioeconomic status (1-5 grades from lowest to highest) (19), smoking during pregnancy, maternal BMI (underweight: $<18.5$, normal weight: $18.5-24.9$, overweight: $25.0-29.9$, and obesity: $\geq 30.0)$ (20), placental abruption, SGA, pregestational diabetes, gestational diabetes (21), chronical hypertension, and pre-eclampsia/eclampsia (22).

Pre-eclampsia/eclampsia was defined as gestational hypertension plus any of the following documented symptoms: gestational proteinuria, oliguria, pulmonary edema, or convulsion from $25 \mathrm{wk}$ of gestation to $5 \mathrm{wk}$ postpartum. Hypertension was defined as 2 diastolic blood pressures $\geq 90$ and $\leq 109 \mathrm{~mm} \mathrm{Hg}$ or 1 diastolic pressure $\geq 110 \mathrm{~mm}$ $\mathrm{Hg}$ from $24 \mathrm{wk}$ gestational age to $2 \mathrm{wk}$ postpartum in the absence of a history of chronic renal disease or hypertension before pregnancy, and the absence of elevated diastolic blood pressure at $<24 \mathrm{wk}$ gestational age or $>2 \mathrm{wk}$ postpartum. Proteinuria was defined as $1+$ urinary protein on at least 2 occasions or $2+$ on at least 1 occasion antepartum (or $3+$ intrapartum), in the absence of a history of chronic renal disease and the absence of proteinuria at $<24 \mathrm{wk}$ gestation or $>2 \mathrm{wk}$ postpartum (23). The diagnosis of hypertensive disorders in the current study was based on the actual blood pressure values as recorded in the data files, rather than on diagnostic summaries completed at the time. Detailed description was provided elsewhere (24). SGA infant was defined as one whose birth weight was less than the 10th percentile for a given gestational week in accordance with the global reference weight percentiles calculator in different race and sex, respectively (25). Placental abruption was defined as the complete or partial separation of a normally located placenta from its uterine site before the delivery of fetus (26). The presence of placental abruption was determined at the time of delivery by the attending physician, according to clinical criteria (27). In the present study, all subjects were divided into two groups based on the presence of SGA, pre-eclampsia/eclampsia or abruption. Each group was further divided into two subgroups according to whether hypospadias existed or not. Thus, Subgroup A = Subjects without any pregnancy complication and hypospadias; Subgroup B = Subjects with hypospadias only; Subgroup C = Subjects with pregnancy complications only; Subgroup D = Subjects with both pregnancy complications and hypospadias.

\section{Statistical Analysis}

Maternal characteristics and perinatal outcomes were analyzed using chi-square tests. The association between hypospadias and placental pathology was evaluated by logistic regression. Model 1 presented the unadjusted association. Model 2 adjusted for race, smoking during pregnancy and gestational age.

\section{RESULTS}

In 12,407 subjects (84.8\%) who were not complicated by PMPC, the prevalence of hypospadias was 9 per 1,000 boys. Among 2,230 (15.2\%) subjects who had PMPC, the prevalence was 22 per 1,000 boys. Compared with the controls, hypospadias cases had higher incidence of pregnancy complications: SGA (odds ratio (OR): 2.7, 95\% CI: 1.8, 3.4), abruption (OR: 2.5, 95\% CI: 1.2, 5.4) and pre-eclampsia/eclampsia (OR: 2.3, 95\% CI: 1.2, 4.5) (Table 2).

Table 3 shows that in subjects without pregnancy complications, no significant difference in maternal characteristics was found between hypospadias cases and normal controls. In subjects with any pregnancy complications, mothers of hypospadias infants were more likely to deliver prematurely and be smokers during pregnancy but less likely to be African-American.

Table 4 represents the comparison between hypospadias cases and controls with or without PMPC, respectively. Subgroup D had higher risks of low placental weight (adjusted OR (aOR), 2.7; 95\% CI: $1.3,5.9$ ), infarcts larger than $3 \mathrm{~cm}$ (aOR, 2.6; 95\% CI: $1.1,6.4$ ), vessel atheroma in decidua (aOR, 6.6; 95\% CI: 1.4, 30.8 ), villous infarcts in intervillous space (aOR, 2.0; 95\% CI: 1.0, 4.0), maternal floor infarcts (aOR, 4.7; 95\% CI: 1.0, 21.7), membranous insertion of cord (aOR, 3.8; 95\% CI: 1.3, 11.2) and calcification throughout the cut surface (aOR, 2.5; CI: 1.0, 6.1), than Subgroup $\mathrm{C}$ after adjusting for potential confounders. In contrast, no significant difference in placental pathology was found between Subgroups A and B. We also compared placental pathology between hypospadias cases and nonhypospadias subjects with other major accompanying anomalies and congenital syndromes that we excluded in the current study. As expected, no significant difference was discovered (Supplementary Tables S1 and S2 online). 


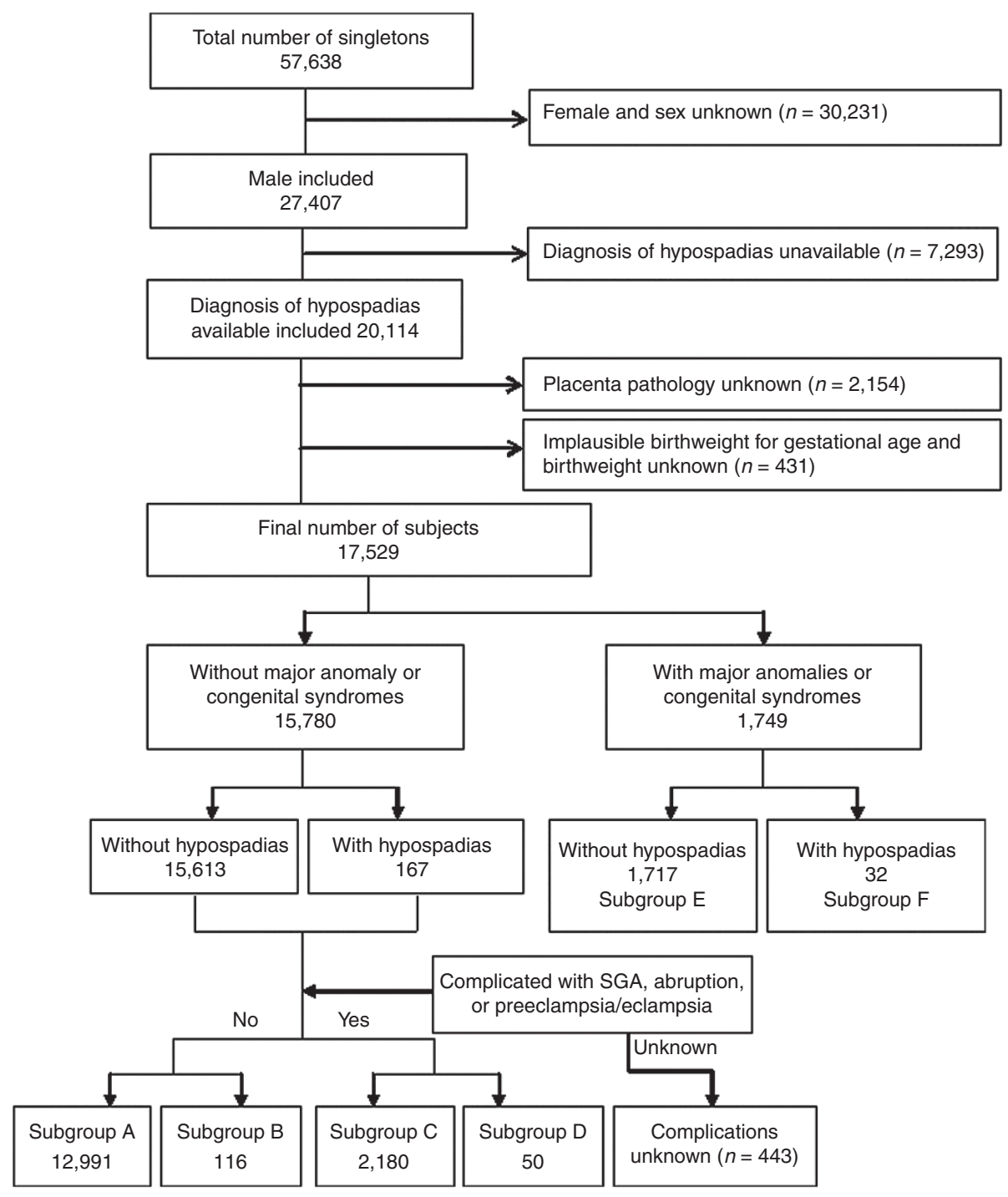

Figure 1. Study subjects flow chart.

\section{DISCUSSION}

In the current study, the prevalence of hypospadias is approximately 11 per 1,000 boys. One third of hypospadias cases were complicated with SGA, placental abruption, or pre-eclampsia/ eclampsia, a substantial proportion of which were considered as PMPC (10). The relative risk of having hypospadias was two times higher in subjects with PMPC than those without. Placental pathology findings further confirmed that hypospadias cases had higher risks of placental lesions.

In subjects with PMPC, we found a high risk of hypospadias boys born with a low placental weight, which was consistent with a large study that included 1,713 hypospadias cases (28). However, that study did not have information on placental pathology. To our knowledge, only two studies examined the association between placental pathology and hypospadias. They only assessed this relationship in SGA (9) and extremely to very-low-birth-weight (11) infants, respectively. Fujimoto et al. showed that placenta-to-fetal weight ratio and placental weight-to-fetal age ratio were significantly higher in patients with hypospadias $(P<0.01)$ and placental histopathologic study revealed that infarction, calcification, and degenerative changes was more pronounced in hypospadias cases than controls. But the differences did not reach statistical significance (11). Yinon et al. reported that in 30 early-onset SGA fetus with hypospadias, $70 \%$ of them exhibited absent/reversed end-diastolic flow in the umbilical arteries and $81 \%$ of them presented ischemic-thrombotic placental pathology, both of which were related to placental insufficiency. However, they did not enroll controls in the study. Our study has more subjects with PMPC and found a significant association between placental pathology and hypospadias.

What does the association between hypospadias and placental pathology or PMPC mean? First, there may be underlying factors that cause both placental pathology and hypospadias. For example, Ephrin (Eph) receptors and their ligands, the ephrins, regulate a wide spectrum of pathophysiological processes, including cellular adhesion, migration or chemo-repulsion and tissue/cell boundary formation. Dysregulated Eph/ 


\section{Articles $\mid$ Chen etal.}

Table 1. Definition of placenta pathological lesions in the Collaborative Perinatal Project, 1959-1966

\begin{tabular}{|c|c|}
\hline Placental pathology & Definition \\
\hline \multicolumn{2}{|l|}{ Placental weight } \\
\hline Placental weight $<10$ th percentile & Proportion of placental weight lower than 10th percentile for a given gestational week \\
\hline \multicolumn{2}{|l|}{ Vascular lesions } \\
\hline \multicolumn{2}{|l|}{ Infarcts in cut surface } \\
\hline Large size of infarct & At least one infarct $\geq 3 \mathrm{~cm}$ in the cut surface \\
\hline Number of infarcts & Total number of infarcts in the maternal surface \\
\hline Thrombosis in cut surface & Vessels thrombosis in the cut surface \\
\hline Vessel atheroma in decidua & Vessels atheroma in the decidua \\
\hline Maternal floor infarcts & Cut surface: maternal floor infarcts \\
\hline Membranous insertion of cord & Membranous insertion \\
\hline \multicolumn{2}{|l|}{ Inflammatory cell infiltration } \\
\hline Neutrophilic infiltration & $\begin{array}{l}\text { Neutrophilic infiltration in the deciduas, in the chorion or amnion of membrane roll, or at } \\
\text { the chorion of placental surface, or in the umbilical vessels or cord substance }\end{array}$ \\
\hline Lymphocytic infiltration & Lymphocytic infiltration in the capsularis or basalis or at the margin \\
\hline Hemorrhage & Occurrence of hemorrhage in the maternal surface or thrombosis in the intervillous space \\
\hline Calcification & Calcification throughout the cut surface \\
\hline
\end{tabular}

PBW, Placenta-to-birth weight ratio.

Table 2. Maternal pregnancy complications and comorbidities by hypospadias in the Collaborative Perinatal Project, 1959-1966

\begin{tabular}{|c|c|c|c|c|}
\hline Characteristics & $\begin{array}{c}\text { Without } \\
\text { hypospadias } \\
\text { (Ref) }\end{array}$ & $\begin{array}{c}\text { With } \\
\text { hypospadias }\end{array}$ & OR $(95 \% \mathrm{Cl})$ & $P$ \\
\hline$N(\%)$ & $15,613(98.9)$ & $167(1.1)$ & I & I \\
\hline $\begin{array}{l}\text { Small-for- } \\
\text { gestational-age }\end{array}$ & $1,416(9.3)$ & $36(21.6)$ & $2.7(1.8,3.4)$ & $<0.01$ \\
\hline Abruption & $266(1.7)$ & $7(4.2)$ & $2.5,(1.2,5.4)$ & 0.04 \\
\hline $\begin{array}{l}\text { Pre-eclampsia or } \\
\text { eclampsia }\end{array}$ & $413(2.7)$ & $10(6.0)$ & $2.3(1.2,4.5)$ & 0.02 \\
\hline $\begin{array}{l}\text { Pre-existing } \\
\text { hypertension }\end{array}$ & $1,167(7.5)$ & $9(5.4)$ & $0.7(0.4,1.4)$ & 0.3 \\
\hline $\begin{array}{l}\text { Gestational } \\
\text { diabetes }\end{array}$ & $154(1.0)$ & $3(1.8)$ & $1.8(0.6,5.8)$ & 0.29 \\
\hline $\begin{array}{l}\text { Pre-existing } \\
\text { diabetes }\end{array}$ & $227(1.5)$ & $9(5.4)$ & $3.9(2.0,7.6)$ & $<0.01$ \\
\hline
\end{tabular}

Bold font: $P<0.05 . /$ : no available number.

ephrin signaling in the genital tubercle vascular endothelia has been linked to the failure of midline fusion of the urethral fold. They are also associated with failed maternal spiral artery remodeling $(29,30)$. Thus, if a factor affects the ephrin system, it will cause both hypospadias and poor placental implantation. Similarly, fibroblast growth factor is an androgen-induced growth factor while epidermal growth factor is regulated by human chorionic gonadotropin (hCG) and both of them are crucial for embryonic development $(31,32)$. Low expression of these growth factors are involved in hypospadias and may reduce placental vascular development, which will lead to poor placental function and fetal growth retardation/pre-eclampsia $(33,34)$. We speculate that low and moderate level of perturbations may only cause placental pathology while a high level could result in not only more severe placental pathology but also hypospadias. Further research is warranted to elucidate the underlying biological mechanisms.

It is also possible that some hypospadias cases are the consequence of placental pathology/insufficiency. Studies suggested that early placental insufficiency might affect both hormone secretion (including hCG and androgen) and fetal nutrition $(33,35)$. Animal models confirmed that hCG could stimulate human fetal testis that is xenografted into male mice to secrete testosterone (36). Thus, low hCG level and, in turn, low fetal androgen concentration may lead to male genital malformation, e.g., hypospadias and cryptorchidism, by impairing fetal androgen signaling or dysregulating expression of progesterone receptors in the developing genital tubercle $(37,38)$. Moreover, there may be a programming window and only within this window can antiandrogenic xenobiotics induce hypospadias, cryptorchidism and altered penile length and other genital malformation while androgens may accelerate urethral fold fusion and a longer urethral tube in male rats 
Table 3. Maternal characteristics by subgroup in the Collaborative Perinatal Project, 1959-1966

\begin{tabular}{|c|c|c|c|c|c|c|}
\hline \multirow[b]{2}{*}{ Characteristics } & \multicolumn{3}{|c|}{ Pregnancy without placenta-mediated complications } & \multicolumn{3}{|c|}{ Pregnancy with placenta-mediated complications } \\
\hline & $\begin{array}{l}\text { Without hypospadias } \\
\text { Subgroup A }\end{array}$ & $\begin{array}{l}\text { With hypospadias } \\
\text { Subgroup B }\end{array}$ & $P$ value & $\begin{array}{l}\text { Without hypospadias } \\
\text { Subgroup C }\end{array}$ & $\begin{array}{l}\text { With hypospadias } \\
\text { Subgroup D }\end{array}$ & $P$ value \\
\hline$N(\%)$ & Mean (SD) & Mean (SD) & & Mean (SD) & Mean (SD) & \\
\hline Maternal age (year) & $24.5(6.1)$ & $24.8(5.9)$ & 0.74 & $24.4(6.5)$ & $25.0(6.3)$ & 0.78 \\
\hline Gestational age (week) & $N(\%)$ & $N(\%)$ & & $N(\%)$ & $N(\%)$ & \\
\hline Race & & & 0.81 & & & 0.02 \\
\hline White & $6,540(52.1)$ & $61(52.6)$ & & $1,162(53.3)$ & $28(56.0)$ & \\
\hline African-American & $5,998(47.7)$ & $52(44.8)$ & & $950(43.6)$ & $17(34.0)$ & \\
\hline Less than high school $(\leq 9)$ & $3,433(26.4)$ & $29(25.0)$ & & $694(31.8)$ & $11(22.0)$ & \\
\hline High school (10-12) & $7,901(60.8)$ & $73(62.9)$ & & $1,224(56.2)$ & $29(58.0)$ & \\
\hline College and above (> 12) & $1,657(12.8)$ & $14(12.1)$ & & $262(12.0)$ & $10(20.0)$ & \\
\hline Social economic status & & & 0.95 & & & 0.10 \\
\hline 1 (Lowest) & $849(6.7)$ & $8(7.0)$ & & $188(8.8)$ & $2(4.1)$ & \\
\hline 2 & $3,738(29.3)$ & $35(30.7)$ & & $632(29.7)$ & $14(28.6)$ & \\
\hline 3 & $4,016(31.3)$ & $36(31.6)$ & & $627(29.5)$ & $9(18.4)$ & \\
\hline 4 & $2,732(21.4)$ & $21(18.4)$ & & $449(21.1)$ & $17(34.7)$ & \\
\hline Maternal BMI (kg/m²) & & & 0.92 & & & 0.63 \\
\hline$<18.5$ & $1,730(13.5)$ & $15(12.9)$ & & $347(16.4)$ & $9(18.7)$ & \\
\hline $18.5-25$ & $8,300(64.6)$ & $74(63.8)$ & & $1,350(63.6)$ & $33(68.7)$ & \\
\hline $25-30$ & $1,910(14.9)$ & $17(14.7)$ & & $241(11.4)$ & $3(6.3)$ & \\
\hline$\geq 30$ & $894(7.0)$ & $10(8.6)$ & & $182(8.6)$ & $3(6.3)$ & \\
\hline
\end{tabular}

Subgroup A: Subjects without any pregnancy complication and hypospadias. Subgroup B: Subjects with hypospadias only. Subgroup C: Subjects with pregnancy complications only. Subgroup D: Subjects with both pregnancy complications and hypospadias.

Bold font: $P<0.05$.

$(39,40)$. In humans, the window is more likely to be $8-14 \mathrm{wk}$ of gestation (39). Therefore, during the vulnerable period if the level of hCG is low, the development of external genitalia may be affected.

Thus, both the confounding effect by unknown factors and a causal inference of placental pathology are plausible in the development of hypospadias. Nonetheless, our study clearly indicates that hypospadias cases may have different etiologies because only one-third of hypospadias cases were involved in placental pathology. More cases had no detectable placental pathology.
Our study has several strengths. The CPP remains the largest prospective birth cohort study in the United States, which collected standardized information on maternal characteristics, medical and obstetrical events, and systemically followed up the children for 7-8 y. The latter may explain why our study has a little higher prevalence of hypospadias than some other studies (1-4,41-43). Second, placentas from the vast majority of pregnancies $(82 \%)$ were examined, blind to clinical events and according to a standardized protocol. It has been the most comprehensive placenta database in history. Finally, pre-eclampsia/eclampsia, placenta abruption, and poor 
Articles | Chen etal.

Table 4. Comparison of placental pathology lesions by subgroup in the Collaborative Perinatal Project, 1959-1966

\begin{tabular}{|c|c|c|c|c|c|c|c|c|}
\hline \multirow[b]{2}{*}{ Placenta pathological lesions } & \multicolumn{4}{|c|}{ Pregnancy without placenta-mediated complications } & \multicolumn{4}{|c|}{ Pregnancy with placenta-mediated complications } \\
\hline & $\begin{array}{l}\text { Subgroup } \\
\text { A (Ref) }\end{array}$ & $\begin{array}{l}\text { Subgroup } \\
\text { B }\end{array}$ & $\begin{array}{l}\text { Crude OR } \\
(95 \% \mathrm{Cl})\end{array}$ & $\begin{array}{l}\text { Adjusted } \\
\mathrm{OR}(95 \% \mathrm{Cl})\end{array}$ & $\begin{array}{l}\text { Subgroup } \\
\text { C (Ref) }\end{array}$ & $\begin{array}{l}\text { Subgroup } \\
\text { D }\end{array}$ & $\begin{array}{l}\text { Crude OR } \\
(95 \% \mathrm{Cl})\end{array}$ & $\begin{array}{l}\text { Adjusted OR } \\
\qquad(95 \% \mathrm{Cl})\end{array}$ \\
\hline \multicolumn{9}{|l|}{ Placental weight } \\
\hline Placental weight $<10$ th percentile & $134(1.0)$ & $1(0.9)$ & $0.8(0.1,6.1)$ & $0.9(0.1,6.3)$ & $152(7.0)$ & $9(18.4)$ & $3.0(1.4,6.3)$ & $2.7(1.3,5.9)$ \\
\hline \multicolumn{9}{|l|}{ Infarcts in cut surface } \\
\hline Occurrence of old vascular infarcts & $1,097(8.5)$ & $6(5.2)$ & $0.5(0.2,1.3)$ & $0.6(0.3,1.4)$ & $268(12.3)$ & $10(20.0)$ & $1.8(0.9,3.6)$ & $1.9(0.9,3.9)$ \\
\hline Large size of infarct & $411(3.2)$ & $2(1.7)$ & $0.6(0.3,1.3)$ & $0.5(0.1,2.2)$ & $109(5.0)$ & $6(12.0)$ & $2.6(1.1,6.2)$ & $2.6(1.1,6.4)$ \\
\hline Number of infarcts & $578(4.5)$ & $5(4.3)$ & $0.5(0.1,2.2)$ & $1.0(0.4,2.4)$ & $159(7.3)$ & $5(10.2)$ & $1.4(0.6,3.7)$ & $1.6(0.6,4.1)$ \\
\hline Villous infarcts in intervillous space & $1,781(13.7)$ & $12(10.3)$ & $0.7(0.4,1.3)$ & $0.7(0.4,1.4)$ & $336(15.4)$ & $12(24.0)$ & $1.7(0.9,3.3)$ & $2.0(1.0,4.0)$ \\
\hline $\begin{array}{l}\text { Syncytium-nuclear clumping in } \\
\text { decidua }\end{array}$ & $226(1.9)$ & $2(1.9)$ & $1.0(0.2,4.0)$ & $1.0(0.2,4.0)$ & $67(3.6)$ & $3(7.5)$ & $2.2(0.7,7.3)$ & $2.3(0.7,7.7)$ \\
\hline Maternal floor infarcts & $38(0.3)$ & $0(0)$ & / & / & $16(0.7)$ & $2(4.0)$ & $5.6(1.3,25.1)$ & $4.7(1.0,21.7)$ \\
\hline Membranous insertion of cord & $175(1.4)$ & $1(0.9)$ & $0.6(0.1,4.6)$ & $0.7(0.1,4.7)$ & $49(2.3)$ & $4(8.0)$ & $3.7(1.3,10.8)$ & $3.8(1.3,11.2)$ \\
\hline \multicolumn{9}{|l|}{ Inflammatory cell infiltration } \\
\hline Neutrophilic infiltration & $1,207(9.3)$ & $14(12.1)$ & $1.3(0.8,2.4)$ & $1.2(0.6,2.1)$ & $234(10.7)$ & $7(14.0)$ & $1.4(0.6,3.0)$ & $1.2(0.5,2.6)$ \\
\hline Lymphocytic infiltration & $144(1.1)$ & $1(0.9)$ & $0.8(0.1,5.6)$ & $0.8(0.1,5.8)$ & $29(1.3)$ & $1(2.0)$ & $1.5(0.2,11.3)$ & $1.1(0.1,8.5)$ \\
\hline Hemorrhage & $950(7.3)$ & $8(6.9)$ & $0.9(0.5,1.9)$ & $1.0(0.5,2.0)$ & $225(10.3)$ & $3(6.0)$ & $0.6(0.2,1.8)$ & $0.5(0.2,1.7)$ \\
\hline
\end{tabular}

Subgroup A: Subjects without any pregnancy complication and hypospadias. Subgroup B: Subjects with hypospadias only. Subgroup C: Subjects with pregnancy complications only. Subgroup D: Subjects with both pregnancy complications and hypospadias. Crude OR: model 1, unadjusted OR Adjusted OR: model 2, logistic model adjusting for race, smoking and gestational age.

PBW ratio, Placenta-to-birth weight ratio.

Bold font: $P<0.05 . /$ : no available number.

intrauterine growth are all closely associated with placental insufficiency and, therefore, are commonly defined as PMPC. Integration of these three conditions may be a more effective approach to explore the relationship between placental pathology and hypospadias.

Nonetheless, the CPP did not record the severity and family history of hypospadias. It is hypothesized that maternal-placental factor may cause severe hypospadias (defined anatomically as perineal, penoscrotal, or proximal) (44) while genetic susceptibility and environmental chemicals are more likely to be responsible for mild hypospadias (defined as distal) $(7,8,45)$. Since a cause can be identified only in $30 \%$ of severe hypospadias cases (33), however, placental pathology may be another indicator for potential different pathogenic etiologies. Finally, with 167 hypospadias cases, our sample size is still limited.

In conclusion, our study confirms the association between placental pathology resulting from placental insufficiency and hypospadias, and indicates that hypospadias may have different etiologies. It provides important clues on the pathogenesis of some hypospadias cases. A larger-scale and more informative prospective study may provide further valuable insight into the molecular mechanism of placenta-associated hypospadias for possible early prevention.

\section{SUPPLEMENTARY MATERIAL}

Supplementary material is linked to the online version of the paper at http://www.nature.com/pr

\section{AUTHOR CONTRIBUTORS}

Yan Chen and Luming Sun designed the study. Yan Chen and Xiaoping Lei did the statistical analyses. Jun Zhang provided important input and substantially revised the manuscript. Hongquan Geng critically reviewed the manuscript. Yan Chen and Luming Sun contributed equally and are the co-first authors. All authors have read and approved the final version of the manuscript and no conflict of interest was disclosed.

\section{STATEMENT OF FINANCIAL SUPPORT}

This work was supported by Shanghai Science \& Technology Commission Foundation of China (grant number12ZR1423900) and National Education Commission of China (grant number 20130073110012).

Disclosure: All authors have approved the submission and no conflict of interest was disclosed. 


\section{REFERENCES}

1. Nassar N, Bower C, Barker A. Increasing prevalence of hypospadias in Western Australia, 1980-2000. Arch Dis Child 2007;92:580-4.

2. Ghirri P, Scaramuzzo RT, Bertelloni S, et al. Prevalence of hypospadias in Italy according to severity, gestational age and birthweight: an epidemiological study. Ital J Pediatr 2009;35:18.

3. Mohammadzadeh A, Farhat A, Esmaieli H, Shiranzaei S. Prevalence and risk factors of hypospadias in a private hospital in northeast iran. Iran J Pediatr 2011;21:497-501.

4. Carlson WH, Kisely SR, MacLellan DL. Maternal and fetal risk factors associated with severity of hypospadias: a comparison of mild and severe cases. J Pediatr Urol 2009;5:283-6.

5. Baskin LS, Erol A, Jegatheesan P, Li Y, Liu W, Cunha GR. Urethral seam formation and hypospadias. Cell Tissue Res 2001;305:379-87.

6. Jensen MS, Wilcox AJ, Olsen J, et al. Cryptorchidism and hypospadias in a cohort of 934,538 Danish boys: the role of birth weight, gestational age, body dimensions, and fetal growth. Am J Epidemiol 2012;175: 917-25.

7. Brouwers MM, van der Zanden LF, de Gier RP, et al. Hypospadias: risk factor patterns and different phenotypes. BJU Int 2010;105:254-62.

8. van Rooij IA, van der Zanden LF, Brouwers MM, Knoers NV, Feitz WF, Roeleveld N. Risk factors for different phenotypes of hypospadias: results from a Dutch case-control study. BJU Int 2013;112:121-8.

9. Yinon Y, Kingdom JC, Proctor LK, et al. Hypospadias in males with intrauterine growth restriction due to placental insufficiency: the placental role in the embryogenesis of male external genitalia. Am J Med Genet A 2010;152A:75-83.

10. Sun LM, Walker MC, Cao HL, Yang Q, Duan T, Kingdom JC. Assisted reproductive technology and placenta-mediated adverse pregnancy outcomes. Obstet Gynecol 2009;114:818-24.

11. Seferovic MD, Gupta MB. Increased umbilical cord PAI-1 levels in placental insufficiency are associated with fetal hypoxia and angiogenesis. Dis Markers 2016;2016:7124186.

12. Fujimoto T, Suwa T, Kabe K, Adachi T, Nakabayashi M, Amamiya T. Placental insufficiency in early gestation is associated with hypospadias. J Pediatr Surg 2008;43:358-61.

13. Hardy JB. The Collaborative Perinatal Project: lessons and legacy. Ann Epidemiol 2003;13:303-11.

14. Alexander GR, Himes JH, Kaufman RB, Mor J, Kogan M. A United States national reference for fetal growth. Obstet Gynecol 1996;87:163-8.

15. Naeye RL. Effects of maternal cigarette smoking on the fetus and placenta. Br J Obstet Gynaecol 1978;85:732-7.

16. Ghidini A, Salafia CM, Pezzullo JC. Placental vascular lesions and likelihood of diagnosis of preeclampsia. Obstet Gynecol 1997;90(4 Pt 1):542-5.

17. Redline RW. Placental pathology: a systematic approach with clinical correlations. Placenta 2008;29 Suppl A:S86-91.

18. Redline RW, Heller D, Keating S, Kingdom J. Placental diagnostic criteria and clinical correlation-a workshop report. Placenta 2005;26 Suppl A:S114-7.

19. Myrianthopoulos NC, French KS. An application of the U.S. Bureau of the Census socioeconomic index to a large, diversified patient population. Soc Sci Med 1968;2:283-99.

20. Obesity: preventing and managing the global epidemic. Report of a WHO consultation. World Health Organ Tech Rep Ser 2000; 894:i-xii, 1-253.

21. Baptiste-Roberts K, Nicholson WK, Wang NY, Brancati FL. Gestational diabetes and subsequent growth patterns of offspring: the National Collaborative Perinatal Project. Matern Child Health J 2012;16:125-32.

22. Zhang J, Troendle JF, Levine RJ. Risks of hypertensive disorders in the second pregnancy. Paediatr Perinat Epidemiol 2001;15:226-31.

23. Ness RB, Zhang J, Bass D, Klebanoff MA. Interactions between smoking and weight in pregnancies complicated by preeclampsia and smallfor-gestational-age birth. Am J Epidemiol 2008;168:427-33.
24. Zhang J, Klebanoff MA, Roberts JM. Prediction of adverse outcomes by common definitions of hypertension in pregnancy. Obstet Gynecol 2001;97:261-7.

25. Mikolajczyk RT, Zhang J, Betran AP, et al. A global reference for fetalweight and birthweight percentiles. Lancet 2011;377:1855-61.

26. Oyelese Y, Ananth CV. Placental abruption. Obstet Gynecol 2006;108: 1005-16.

27. Ananth CV, Oyelese Y, Prasad V, Getahun D, Smulian JC. Evidence of placental abruption as a chronic process: associations with vaginal bleeding early in pregnancy and placental lesions. Eur J Obstet Gynecol Reprod Biol 2006;128:15-21.

28. Arendt LH, Ramlau-Hansen CH, Wilcox AJ, Henriksen TB, Olsen J, Lindhard MS. Placental weight and male genital anomalies: a nationwide Danish Cohort Study. Am J Epidemiol 2016;183:1122-8.

29. Dravis C, Yokoyama N, Chumley MJ, et al. Bidirectional signaling mediated by ephrin-B2 and EphB2 controls urorectal development. Dev Biol 2004;271:272-90.

30. Chatzizacharias NA, Giaginis CT, Agapitos E, Theocharis SE. The role of ephrins' receptors and ephrins' ligands in normal placental development and disease. Expert Opin Ther Targets 2014;18:269-75.

31. Liu SB, Ma Z, Sun WL, et al. The role of androgen-induced growth factor (FGF8) on genital tubercle development in a hypospadiac male rat model of prenatal exposure to di-n-butyl phthalate. Toxicology 2012;293:53-8.

32. Han XB, Yang XF, Mi ZG. [Human chorionic gonadotrophin regulates epidermal growth factor in the phallus of hypospadias mice]. Zhonghua Nan Ke Xue 2008;14:884-7.

33. van der Zanden LF, van Rooij IA, Feitz WF, Franke B, Knoers NV, Roeleveld N. Aetiology of hypospadias: a systematic review of genes and environment. Hum Reprod Update 2012;18:260-83.

34. Grazul-Bilska AT, Johnson ML, Borowicz PP, et al. Placental development during early pregnancy in sheep: effects of embryo origin on vascularization. Reproduction 2014;147:639-48.

35. Chaddha V, Viero S, Huppertz B, Kingdom J. Developmental biology of the placenta and the origins of placental insufficiency. Semin Fetal Neonatal Med 2004;9:357-69.

36. Mitchell RT, Saunders PT, Childs AJ, et al. Xenografting of human fetal testis tissue: a new approach to study fetal testis development and germ cell differentiation. Hum Reprod 2010;25:2405-14.

37. Spade DJ, Hall SJ, Saffarini CM, Huse SM, McDonnell EV, Boekelheide K. Differential response to abiraterone acetate and di-n-butyl phthalate in an androgen-sensitive human fetal testis xenograft bioassay. Toxicol Sci 2014;138:148-60.

38. Agras K, Shiroyanagi Y, Baskin LS. Progesterone receptors in the developing genital tubercle: implications for the endocrine disruptor hypothesis as the etiology of hypospadias. J Urol 2007;178:722-7.

39. Welsh M, Saunders PT, Fisken M, et al. Identification in rats of a programming window for reproductive tract masculinization, disruption of which leads to hypospadias and cryptorchidism. J Clin Invest 2008;118:1479-90.

40. Yucel S, Cavalcanti AG, Desouza A, Wang Z, Baskin LS. The effect of oestrogen and testosterone on the urethral seam of the developing male mouse genital tubercle. BJU Int 2003;92:1016-21.

41. Canon S, Mosley B, Chipollini J, Purifoy JA, Hobbs C. Epidemiological assessment of hypospadias by degree of severity. J Urol 2012;188:2362-6.

42. Carmichael SL, Shaw GM, Nelson V, Selvin S, Torfs CP, Curry CJ. Hypospadias in California: trends and descriptive epidemiology. Epidemiology 2003;14:701-6.

43. Bergman JE, Loane M, Vrijheid M, et al. Epidemiology of hypospadias in Europe: a registry-based study. World J Urol 2015;33:2159-67.

44. Huisma F, Thomas M, Armstrong L. Severe hypospadias and its association with maternal-placental factors. Am J Med Genet A 2013;161A:2183-7.

45. Brouwers MM, Feitz WF, Roelofs LA, Kiemeney LA, de Gier RP, Roeleveld N. Risk factors for hypospadias. Eur J Pediatr 2007;166:671-8. 